\title{
A rise in NAD precursor nicotinamide mononucleotide (NMN) after injury promotes axon degeneration
}

\author{
M Di Stefano ${ }^{1,8}$, I Nascimento-Ferreira, ${ }^{2,8}$, G Orsomando $^{3}$, V Mori ${ }^{3}$, J Gilley ${ }^{2}$, R Brown ${ }^{4}$, L Janeckova ${ }^{2}$, ME Vargas ${ }^{5,6}$, LA Worrell ${ }^{2}$, A Loreto ${ }^{1}$, \\ J Tickle ${ }^{1}$, J Patrick ${ }^{2}$, JRM Webster ${ }^{1}$, M Marangoni ${ }^{1}$, FM Carpi ${ }^{7}$, S Pucciarelli ${ }^{7}, F$ Rossi ${ }^{1}$, W Meng ${ }^{1}$, A Sagasti ${ }^{6}$, RR Ribchester ${ }^{4}$, G Magni ${ }^{7}$, \\ MP Coleman ${ }^{\star 2,8}$ and L Conforti ${ }^{\star, 1,8}$
}

NAD metabolism regulates diverse biological processes, including ageing, circadian rhythm and axon survival. Axons depend on the activity of the central enzyme in NAD biosynthesis, nicotinamide mononucleotide adenylyltransferase 2 (NMNAT2), for their maintenance and degenerate rapidly when this activity is lost. However, whether axon survival is regulated by the supply of NAD or by another action of this enzyme remains unclear. Here we show that the nucleotide precursor of NAD, nicotinamide mononucleotide (NMN), accumulates after nerve injury and promotes axon degeneration. Inhibitors of NMN-synthesising enzyme NAMPT confer robust morphological and functional protection of injured axons and synapses despite lowering NAD. Exogenous NMN abolishes this protection, suggesting that NMN accumulation within axons after NMNAT2 degradation could promote degeneration. Ectopic expression of NMN deamidase, a bacterial NMN-scavenging enzyme, prolongs survival of injured axons, providing genetic evidence to support such a mechanism. NMN rises prior to degeneration and both the NAMPT inhibitor FK866 and the axon protective protein WId ${ }^{\mathrm{S}}$ prevent this rise. These data indicate that the mechanism by which NMNAT and the related WId ${ }^{S}$ protein promote axon survival is by limiting NMN accumulation. They indicate a novel physiological function for NMN in mammals and reveal an unexpected link between new strategies for cancer chemotherapy and the treatment of axonopathies. Cell Death and Differentiation (2015) 22, 731-742; doi:10.1038/cdd.2014.164; published online 17 October 2014

Axon degeneration in disease shares features with the progressive breakdown of the distal segment of severed axons as described by Augustus Waller in 1850 and named Wallerian degeneration. ${ }^{1}$ The serendipitous discovery of Wallerian degeneration slow $\left(\right.$ Wld $\left.^{\mathrm{S}}\right)$ mice, where transected axons survive 10 times longer than in wild types (WTs), ${ }^{2}$ suggested that axon degeneration is a regulated process, akin to apoptosis of the cell bodies but distinct in molecular terms. ${ }^{3,4}$ This process appears conserved in rats, flies, zebrafish and humans. ${ }^{5-8}$ Wld $^{5}$ blocks axon degeneration in some disease models, indicating a mechanistic similarity. ${ }^{3}$ Therefore understanding the pathway it influences is an excellent route towards novel therapeutic strategies.

$\mathrm{WId}^{\mathrm{S}}$ is a modified nicotinamide mononucleotide adenylyltransferase 1 (NMNAT1) enzyme, whose N-terminal extension partially relocates NMNAT1 from nuclei to axons, conferring gain of function. ${ }^{9,10}$ In mammals, three NMNAT isoforms, nuclear NMNAT1, cytoplasmic NMNAT2 and mitochondrial NMNAT3, catalyse nicotinamide adenine dinucleotide (NAD) synthesis from nicotinamide mononucleotide (NMN) and adenosine triphosphate (ATP; Figure 1a). ${ }^{11,12}$ Several reports indicate $\mathrm{Wld}^{\mathrm{S}}$ protects injured axons by maintaining axonal NMNAT activity. ${ }^{13-15}$ In WT injured axons, without WId ${ }^{\text {, }}$, NMNAT activity falls when the labile, endogenous axonal isoform, NMNAT2, is no longer transported from cell bodies. ${ }^{16}$ NMNAT2 is required for axon maintenance ${ }^{16}$ and for axon growth in vivo and in vitro, ${ }^{17,18}$ and modulation of its stability by palmitoylation ${ }^{19}$ or ubiquitin-dependent processes both in mice or when ectopically expressed in Drosophila ${ }^{19-21}$ has a corresponding effect on axon survival.

WId $^{\mathrm{S}}$ partially colocalizes with mitochondria ${ }^{14,22}$ and was shown to increase mitochondria motility and $\mathrm{Ca}^{2+}$-buffering capacity. $^{23}$ Inhibiting mitochondrial permeability transition pore protects degenerating axons. ${ }^{24}$ However, Wld ${ }^{S}$ is

\footnotetext{
${ }^{1}$ School of Life Sciences, University of Nottingham, Medical School, Queen's Medical Centre, Nottingham NG7 2UH, UK; ${ }^{2}$ The Babraham Institute, Babraham Research Campus, Babraham, Cambridge CB22 3AT, UK; ${ }^{3}$ Department of Clinical Sciences (DISCO), Section of Biochemistry, Polytechnic University of Marche, Via Ranieri 67, Ancona 60131, Italy; ${ }^{4}$ SBMS, University of Edinburgh, Hugh Robson Building, George Square, Edinburgh EH8 9XD, UK; ${ }^{5}$ Jules Stein Eye Institute and Department of Ophthalmology, University of California Los Angeles, Los Angeles, CA 90095, USA; ${ }^{6}$ Department of Molecular Cell and Developmental Biology, University of California, Los Angeles, CA 90095, USA and ${ }^{7}$ School of Biosciences and Biotechnology, University of Camerino, Via Gentile III da Varano, Camerino (MC) 62032, Italy

${ }^{*}$ Corresponding author: MP Coleman, The Babraham Institute, Babraham Research Campus, Babraham, Cambridge CB22 3AT, UK. Tel/Fax: +44 (0) 1223496315 ; E-mail: michael.coleman@babraham.ac.uk

or L Conforti, School of Life Sciences, University of Nottingham, Medical School, Queen's Medical Centre, Nottingham NG7 2UH, UK. Tel: +44 (0)1158231476; Fax: +44 (0)115 823 0142; E-mail: laura.conforti@nottingham.ac.uk

${ }^{8}$ These authors contributed equally to this work.

Abbreviations: ANOVA, analysis of variance; ATP, adenosine triphosphate; cDNA, complementary DNA; DMEM, Dulbecco's modified eagle's medium; DMSO, dimethyl sulfoxide; DRG, dorsal root ganglia; EC50, effective concentration 50; EGFP, enhanced green fluorescent protein; EPP, end-plate potential; FDB, flexor digitorum brevis; HPLC, high-performance liquid chromatography; MORN4, membrane occupation and recognition nexus repeat containing 4; Na, nicotinic acid; NaAD, nicotinic acid adenine dinucleotide; NAD, nicotinamide adenine dinucleotide; NaMN, nicotinic acid mononucleotide; NAMPT, nicotinamide phosphoribosyltransferase; NMN, nicotinamide mononucleotide; NMNAT, nicotinamide mononucleotide adenylyltransferase; NR, nicotinamide riboside; NRK, NR kinase; ORF, open reading frame; PBS, phosphate-buffered saline; RT-PCR, reverse transcriptase-PCR; SCG, superior cervical ganglia; Wld ${ }^{\mathrm{S}}$, Wallerian degeneration slow; WT, wild type; YFP-H, yellow fluorescent protein

Received 11.4.14; revised 30.7.14; accepted 29.8.14; Edited by G Melino; published online 17.10.14
} 
a

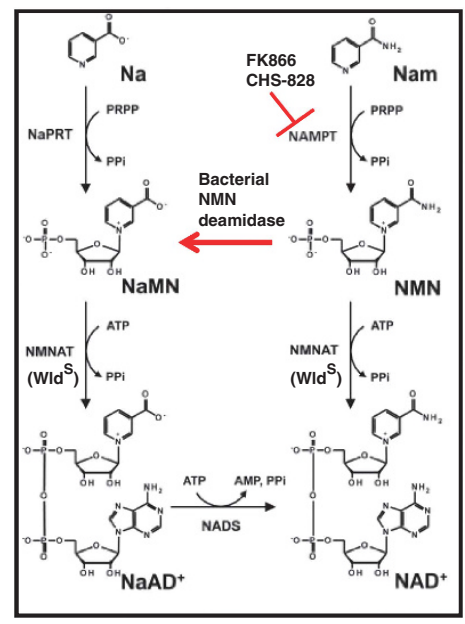

b

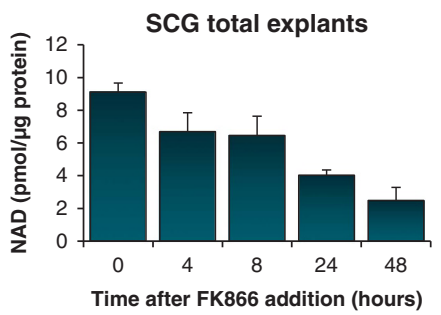

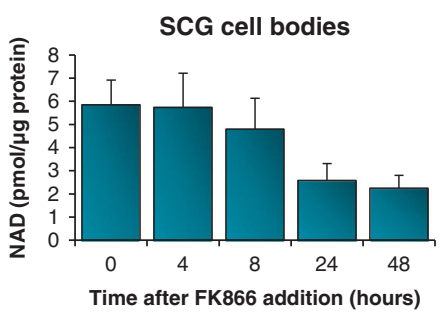

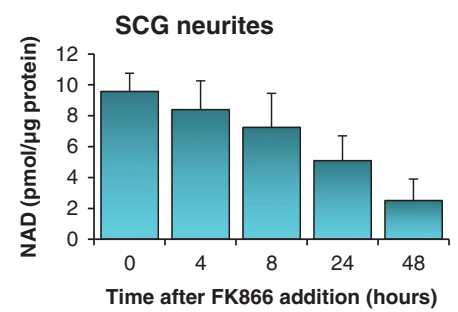

c

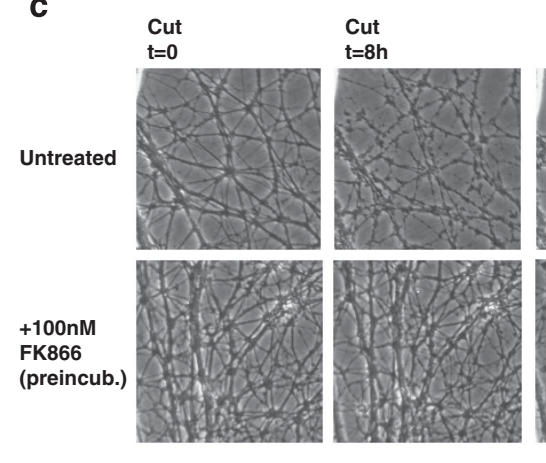

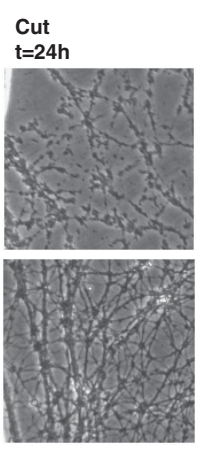

Cut $t=33-36 h$

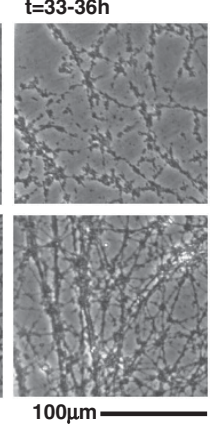

d

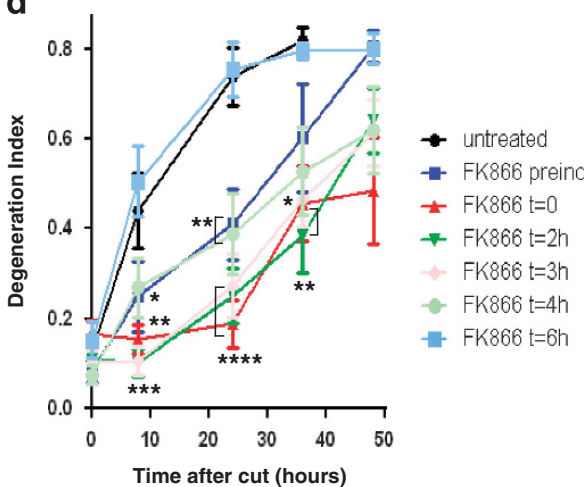

Figure 1 FK866 acts within axons to delay degeneration after injury. (a) The salvage pathway of NAD biosynthesis from nicotinamide (Nam) and nicotinic acid (Na). Only NAD biosynthesis from Nam is sensitive to FK866, which potently inhibits NAMPT while having no effect on nicotinic acid phosphoribosyltransferase (NaPRT). ${ }^{29}$ The reaction catalysed by bacterial NMN deamidase is also shown. (b) SCG explants were treated with $100 \mathrm{nM}$ FK866 for the indicated times, and then the whole explants (top panel) or the cell bodies (bottom left panel) and neurite fractions (bottom right panel) were separately collected. NAD was determined with an HPLC-based method (see Materials and Methods; $n=3$, mean and S.D. shown). (c) SCG neurites untreated (top panels) or treated with $100 \mathrm{nM} \mathrm{FK866} \mathrm{the} \mathrm{day} \mathrm{before} \mathrm{transection} \mathrm{(bottom} \mathrm{panels)} \mathrm{and} \mathrm{imaged} \mathrm{after} \mathrm{transection} \mathrm{at} \mathrm{the}$ indicated time points. (d) SCG explants were treated with $100 \mathrm{nM} \mathrm{FK866} 1$ day before or at the indicated times after cutting their neurites. Degeneration index was calculated from three fields in 2-4 independent experiments. The effect of treatment is highly significant when the drug is preincubated or added at $0-4 \mathrm{~h}$ after cut (mean \pm S.E.M., $n=6-12$, one-way ANOVA followed by Bonferroni's post-hoc test, ${ }^{*} P<0.05,{ }^{\star \star} P<0.01,{ }^{* \star *} P<0.001,{ }^{* \star *} P<0.0001$, compared with untreated)

protective in axons devoid of mitochondria, ${ }^{8}$ and targeting a cytosolic variant of NMNAT2 to mitochondria abolished its protective effect, ${ }^{19}$ suggesting a late mitochondrial involvement in Wallerian degeneration.

Despite the importance of NMNAT activity in axon survival and degeneration, the molecular players remain elusive. Although NMNAT activity is required for protection, ${ }^{13}$ the hypothesis that increased NAD levels are responsible ${ }^{25,26}$ does not fit some data. ${ }^{27,28}$

While further investigating the role of NAD, we found that blocking nicotinamide phosphoribosyltransferase (NAMPT, the enzyme preceding NMNAT, Figure 1a), was surprisingly axon-protective despite lowering NAD. NAMPT catalyses the synthesis of NMNAT-substrate NMN, the rate-limiting step in the NAD salvage pathway from nicotinamide (Nam) (Figure 1a). Here, we show that NMN accumulates after axon injury, and we provide genetic and pharmacological evidence supporting a role for this NMN increase in axon degeneration when NMNAT2 is depleted. We reveal an unexpected new direction for research into the degenerative mechanism, a novel class of protective proteins and new players in an axondegeneration pathway sensitive to drugs under development for cancer.

\section{Results}

NAMPT inhibitor FK866 acts within axons to delay degeneration after injury. To test whether intra-axonal NAD depletion affects injury-induced axon degeneration we used FK866, a potent and specific inhibitor of NAMPT ${ }^{29}$ (Figure 1a). As in other cell types ${ }^{29-31}$ FK866 promptly lowered NAD in cultured superior cervical ganglia (SCG) explants, neurites and cell bodies (Figure 1b). These remained healthy for $>72 \mathrm{~h}$ (Supplementary Figures S1A and S5). Surprisingly, 1-100 nM FK866 added 1 day before neurite transection potently promoted axon survival (Figures 1c-d; Supplementary Figures S1B and C). Protection was optimal when FK866 was added 0-3h postaxotomy and 
detectable when added $4 \mathrm{~h}$ after axotomy (Figure 1d), the time when cut WT neurites commit to degenerate. ${ }^{16}$ FK866 does not affect rapid turnover of NMNAT2 in cut neurites, so protection does not reflect stabilizing NMNAT2 (Supplementary Figure S1D).

These results were reproducible in dorsal root ganglia (DRG) explants (Supplementary Figure S2). A second NAMPT inhibitor, CHS-828, also protected injured neurites at slightly higher concentrations consistent with its lower potency $^{32}$ (Supplementary Figures S3A-C). The presence of NAMPT in SCG neurites (Supplementary Figures S3D-F) is consistent with FK866 and CHS-828 exerting their protective effects by blocking its action within axons.

Thus NAMPT inhibitors unexpectedly phenocopy $\mathrm{Wld}^{\mathrm{S}}$, preserving axons locally, independent of any effects on the nucleus or soma.

A rise in NMN promotes Wallerian degeneration. NAMPT inhibition by FK866 and maintenance of NMNAT activity by WId ${ }^{S}$ both preserve transected axons, but they have opposite effects on flux through the NAD salvage pathway (Figure 1a). However, a common feature is preventing an increase in
NMN, the product of NAMPT and substrate of NMNAT, once NMNAT2 is degraded. Therefore, we tested the hypothesis that NMN promotes axon degeneration.

First, we confirmed that NAMPT persists for $>24 \mathrm{~h}$ in transected SCG neurites (Supplementary Figures S3E and F), long after NMNAT2 degrades, indicating NMN synthesis continues when it can no longer be converted to NAD. ${ }^{16}$ Second, we tested whether exogenous NMN could overcome FK866 to restore rapid axon degeneration. $25 \mu \mathrm{M}-1 \mathrm{mM} \mathrm{NMN}$, co-administered with FK866, dose-dependently reverted neurite protection (Figures $2 \mathrm{a}$ and $\mathrm{b}$ ). The EC50 at $8 \mathrm{~h}$ was $60 \mu \mathrm{M}$, and degeneration was complete at all NMN concentrations tested by $24 \mathrm{~h}$ after injury (Figure 2b), with some reversion even at $2.5 \mu \mathrm{M}$ (data not shown). To exclude intracellular conversion of NMN to NAD, mediated by any residual axonal NMNAT2, we also added $1 \mathrm{mM}$ NMN to FK866-protected neurites $12 \mathrm{~h}$ after cutting, a time when little or no NMNAT2 remains. ${ }^{16}$ Here, NMN restored axon degeneration within $3 \mathrm{~h}$ of addition (Figure $2 \mathrm{~d}$ ).

The likely mechanism of NMN uptake is extracellular conversion to nicotinamide riboside (NR). ${ }^{33-35}$ Although direct uptake of phosphorylated nucleotides may occur, ${ }^{31}$ the a

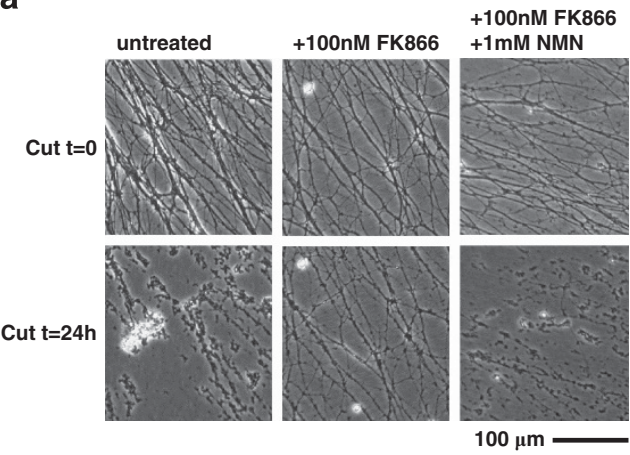

C

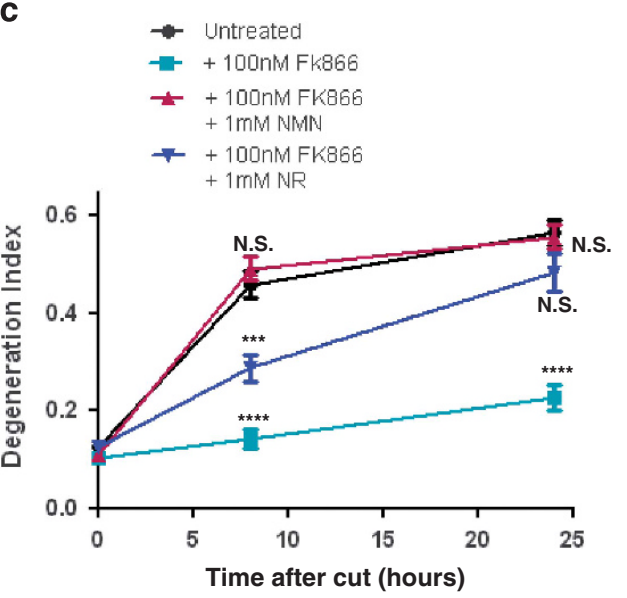

b

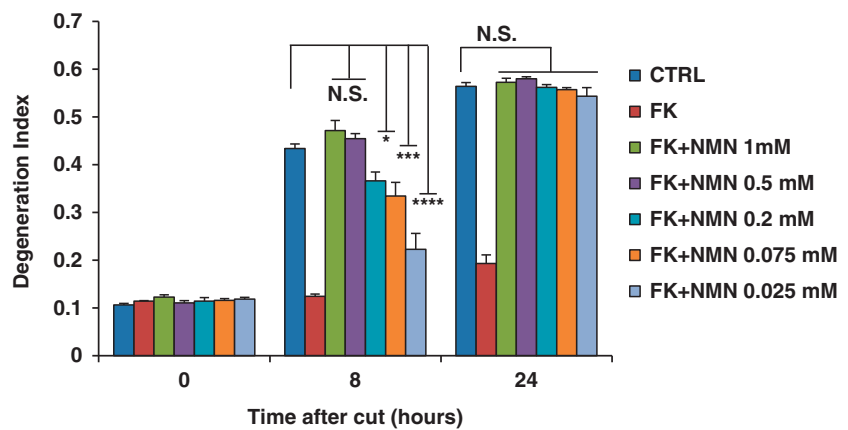

d

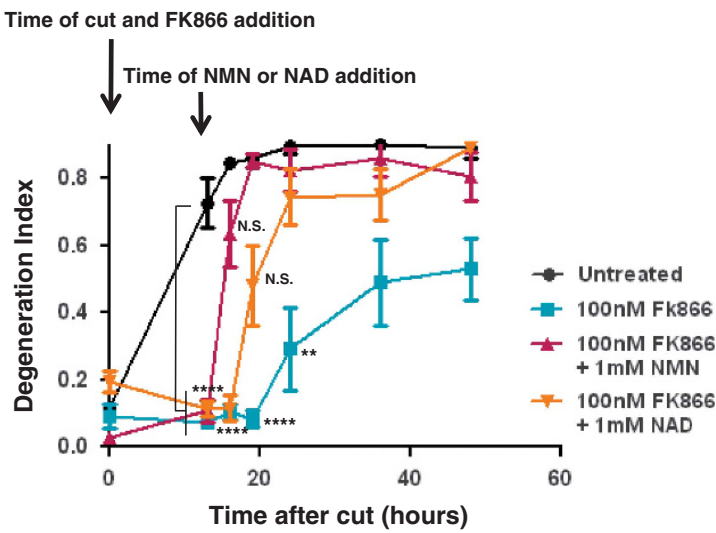

Figure 2 NMN promotes Wallerian degeneration. (a) SCG neurites were cut and then left untreated or treated with $100 \mathrm{nM}$ FK866 or with $100 \mathrm{nM} \mathrm{FK866} \mathrm{and} 1 \mathrm{mM}$ NMN as shown and imaged at the indicated time points. (b) Degeneration index of SCG neurites treated as in panel (a), or with lower NMN concentrations, were calculated from three fields in three independent experiments $\left(n=9\right.$, mean \pm S.E.M., one-way ANOVA with Bonferroni's post-hoc test, ${ }^{*} P<0.05,{ }^{* * *} P<0.001,{ }^{* * * *} P<0.0001$, compared with untreated at the same time point). (c) Degeneration index of SCG neurites cut and then left untreated or treated with $100 \mathrm{nM}$ FK866, $100 \mathrm{nM}$ FK866 and $1 \mathrm{mM}$ NMN or $100 \mathrm{nM}$ FK866 and $1 \mathrm{mM}$ NR as indicated and imaged at 0,8 and $24 \mathrm{~h}$ were calculated in three fields of three independent experiments $(n=9$, mean \pm S.E.M., one-way ANOVA with Bonferroni's post-hoc test, ${ }^{* * *} P<0.001,{ }^{* * * *} P<0.0001$, compared with untreated at the same time point). (d) Degeneration index of SCG neurites cut and then left untreated or treated as indicated was calculated in three fields of three (for NMN effect) or two (for NAD effect) independent experiments $(n=6-9$, mean \pm S.E.M., one-way ANOVA with Bonferroni's post-hoc test, ${ }^{* \star} P<0.01,{ }^{* * \star *} P<0.0001$, compared with untreated at the same time point). NS, not significant 
ectoenzymes nucleotide pyrophosphatase and $5^{\prime}$ nucleotidase are proposed to catalyse two- or one-step conversion of NAD and NMN to $\mathrm{NR}^{33}$ (Supplementary Figure S4A). Intracellular NR kinases (NRKs) use NR to resynthesize NMN ${ }^{36}$ which in turn is used to synthesize NAD, but only if NMNAT is present. Consistently, exogenous NR (Figure 2c) and NAD (Figure 2d; Supplementary Figure S4C) also abolished FK866-induced neurite protection. The likely explanation is that both metabolites feed through to intracellular NMN, but cut axons fail to convert this to NAD. In support, NMN and NAD showed a greatly reduced effect in the presence of inhibitors either of the ectoenzymes converting them to NR or of NR uptake (Supplementary Figures S4B and C). In contrast, nicotinic acid ( $\mathrm{Na})$, nicotinic acid mononucleotide (NaMN) and nicotinic acid adenine dinucleotide (NaAD), all intermediates of NAD synthesis that do not generate NMN but feed into the Preiss-Handler NAD biosynthetic pathway from $\mathrm{Na}$ (also called deamidated pathway, see Figure 1a and Nikiforov et $a l^{33}$ and Belenky et al. ${ }^{34}$ ), were unable to revert FK866-protective effect (Supplementary Figure S5). Their ability to protect cell bodies from long-term FK866 toxicity (Supplementary Figure S5) confirmed they had entered the cell and could be converted to NAD as long as NMNAT activity is present, as this enzyme is required to convert NaMN to NAD (see Figure $1 \mathrm{a}$ and Nikiforov et $a l^{33}$ and Belenky et $a .^{34}{ }^{34}$ ).

Taken together, these results strongly suggest that FK866 protects injured axons by blocking an accumulation of NMN, a nucleotide which $\mathrm{Wld}^{\mathrm{S}}$ and NMNAT2 remove, and consequently that NMN could promote axon degeneration.

NMN promotes Wallerian-like degeneration without physical injury. Degeneration of continuous axons after axonal transport block in some neurodegenerative disorders is mechanistically related to Wallerian degeneration, as $\mathrm{WId}^{\mathrm{S}}$ blocks some of these too. ${ }^{3,37}$ We tested whether FK866 and NMN also influence the Vincristine primary culture model of Wallerian-like degeneration, a pathology underlining chemotherapy-induced peripheral neuropathy. ${ }^{38}$ Here too, $100 \mathrm{nM}$ FK866 protected axons and this was reversed by $1 \mathrm{mM}$ exogenous NMN, indicating a similar degenerative mechanism to that after axotomy (Supplementary Figure S6).

Genetic data confirm that NMN and NAMPT are necessary for rapid Wallerian degeneration. In order to confirm genetically that a rise in NMN promotes axon degeneration, we tested whether axons could be protected by scavenging NMN; the data above suggest that this is also how $\mathrm{Wld}^{\mathrm{S}}$ and NMNAT enzymes promote axon survival so we aimed to replicate this independently of NMNAT. Many bacterial species have an NMN deamidase enzyme that mammals lack. This enzyme converts NMN to NaMN (Figure 1a) and was recently identified and characterized in two bacterial species. ${ }^{39}$ When ectopically expressed in HEK293T or PC12 cells, Escherichia coli NMN deamidase (kindly supplied by Professor Nadia Raffaelli) retains its enzyme activity and promptly converts NMN to NaMN (Figure 3a) without altering NAD levels, as expected (Figure 1a). We then microinjected plasmid complementary DNA (cDNA) constructs encoding E. coli NMN deamidase, fused to enhanced green fluorescent protein (EGFP), into SCG neurons (Figure $3 \mathrm{~b}$ ) and found a robust delay in the degeneration of transected neurites (Figures 3c and d), stronger than the effect of FK866 and similar to that of $\mathrm{Wld}^{\mathrm{S}} .{ }^{27}$ Mutations that greatly reduce catalytic activity (Figure 3a) caused a closely corresponding decline in neurite protection, confirming that NMN deamidase activity is required (Figures $3 c-d$ ). Shewanella oneidensis NMN deamidase also showed robust axon protection (Supplementary Figures S7A-C). In contrast to Wld ${ }^{\mathrm{S}}$, NMN deamidase is unlikely to maintain NAD levels in transected axons as NaMN cannot be converted to NAD due to NMNAT2 rapid degradation. These genetic data indicate that an increase in NMN levels is required for Wallerian degeneration; the ability of NMN deamidase to phenocopy WId $^{\text {S }}$ strongly suggests that both enzymes act by scavenging NMN.

We also sought genetic evidence directly implicating NAMPT. Inhibitors such as FK866 block NAMPT almost instantly but conditional genetic ablation and RNA interference are gradual processes requiring time for messenger RNA and protein turnover; NAMPT is a relatively stable protein in neurites (Supplementary Figures S3E and F). Thus we found that, over the longer period needed to deplete NAMPT genetically, neurons and neurites die, probably reflecting the gradual decline in NAD (Supplementary Figures S1A and S5). Likely NAMPT inhibitors expose a time window when abruptly lowering axonal NMN is protective but depletion of NAD has not yet become harmful, an effect that cannot be mimicked by NAMPT gradual genetic depletion.

To overcome these difficulties, we asked whether expressing a drug-resistant NAMPT mutant restored rapid Wallerian degeneration in the presence of FK866. We engineered the mouse homolog of the human drug-resistant mutant, NAMPT $^{\text {G217R, } 32}$ and showed that, in contrast to WT NAMPT control, it significantly maintained NAD synthesis in HEK293T cells in the presence of FK866 (albeit to only $27 \%$ of that in the absence of the drug), confirming its enzyme activity and drug resistance (Supplementary Figures S7D-F). Although absolute nucleotide levels in axons could differ from HEK293T cells, the relative sensitivities to FK866 of these proteins are likely to be similar. When these cDNA constructs were microinjected into dissociated SCG neurons along with plasmid pDsRed2-N1 to visualize their neurites, even this limited enzyme activity of NAMPT ${ }^{\text {G217R }}$ was sufficient to fully revert neurite protection by FK866 at $24 \mathrm{~h}$ after transection, while the WT, drug-sensitive protein had no effect (Figures 3e-f). Thus NAMPT activity has to be completely silenced for FK866 to protect injured neurites, further illustrating why gradual genetic ablation (above) cannot mimic FK866.

Together, these genetic experiments show that both NMN and NAMPT activity are necessary for rapid Wallerian degeneration and confirm that FK866 protects axons through on-target inhibition of NAMPT.

NMN accumulates in vivo before injured axons degenerate. We then tested in vivo the hypothesis that NMN accumulates in injured axons before degeneration. In WT mice, sciatic nerve axons first fragment around $36 \mathrm{~h}$ after injury. ${ }^{40}$ However, we found that NMN begins to rise within $12 \mathrm{~h}$, reaching 2.5 times normal levels by $30 \mathrm{~h}$ (Figure $4 \mathrm{~A}(\mathrm{a})$ ). Interestingly, this NMN concentration (around $4 \mathrm{nmol} / \mathrm{g}$ ) is 
a

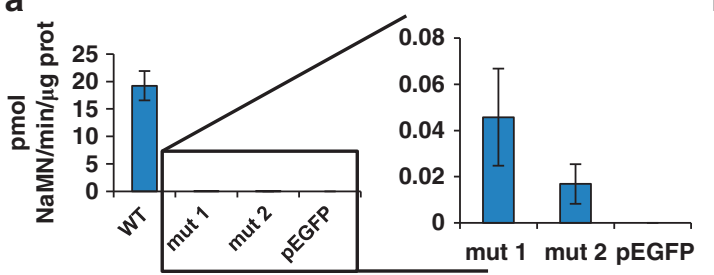

C

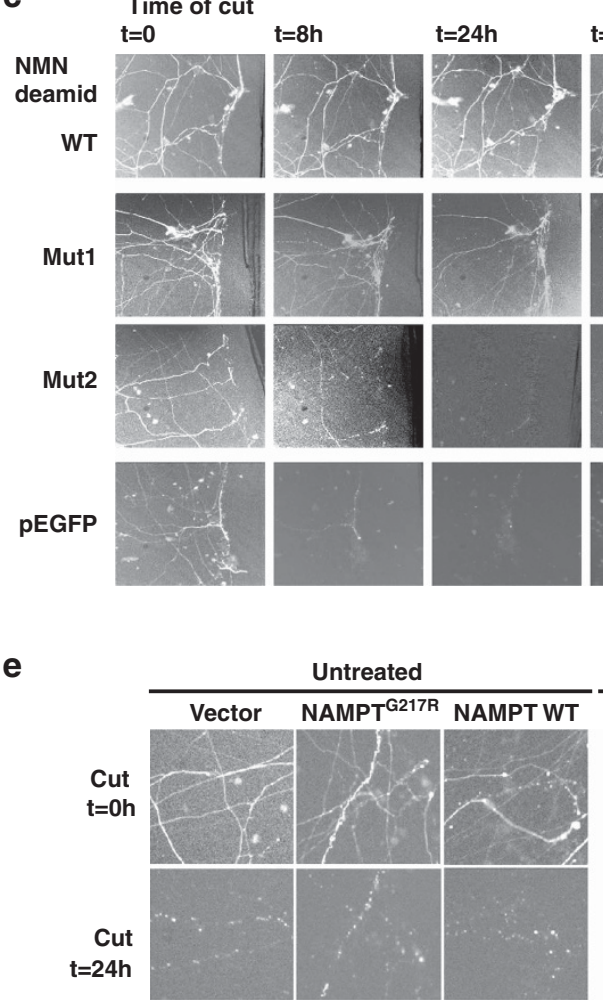

b

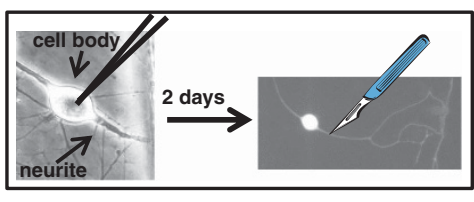

- - pEGFP

- E. coli NMN deamidase WT

- E. E. coli NMN deamidase Mut1

- - E. coli NMN deamidase Mut2
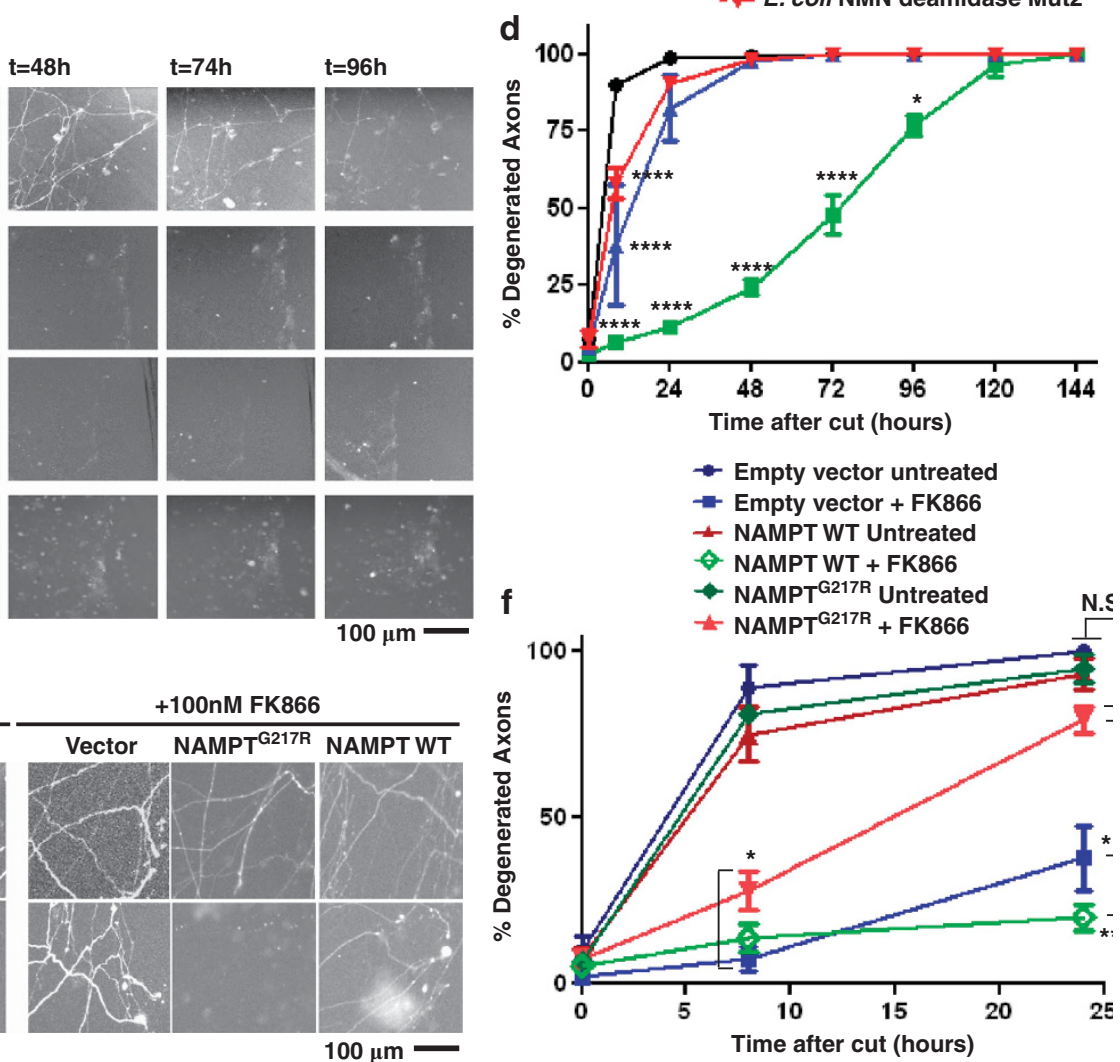

Figure 3 Genetic evidence supporting the role of NMN and NAMPT in axon degeneration. (a) Plasmid CDNA constructs encoding E. coli NMN deamidase WT or its virtually enzymatic inactive mutants Mut1 and Mut2 fused to EGFP, or pEGFP vector alone, were transfected in HEK293T cells. Cells were harvested $48 \mathrm{~h}$ after transfection, lysed and NMN deamidase activity was measured as described in Materials and Methods. Activity of the enzymatically inactive mutants was barely detectable (left panel), but on expanding the y axis it was clearly detectable with respect to cell lysates transfected with pEGFP vector alone (right panel) ( $n=3$, mean and S.D. shown). (b) Schematic representation of microinjection experiment. Nuclei of dissociated SCGs were microinjected with the plasmid together with pDsRed2-N1 for expression of DsRed2 fluorescent marker to visualize individual transfected neurons. Two days after microinjections, fluorescent neurites were cut and imaged at different time points. (c and $\mathbf{d}$ ) NMN deamidase strongly delays degeneration of cut SCG neurites. (c) Constructs expressing WT NMN deamidase or mutants with disrupted enzymatic activity fused to EGFP were microinjected into SCG nuclei along with pDsRed2-N1. EGFP fluorescence within the neurites confirmed expression and homogeneous localization of the expressed proteins in cell bodies and axons. SCG neurites were cut $48 \mathrm{~h}$ after microinjection, and DsRed2 or EGFP images were acquired at different time points after cut as indicated. (d) The percentage of fluorescentdegenerated axons was calculated in five fields of three independent experiments. (mean \pm S.E.M., $n=15$, one-way ANOVA followed by Bonferroni's post-hoc test ${ }^{\star} P<0.05$, ${ }^{* * \star *} P<0.0001$ ). (e and f) Drug-resistant NAMPT restores rapid axon degeneration. (e) Representative images of SCG neurites 0 and $24 \mathrm{~h}$ after cutting and microinjected as in panel (b) with empty vector or with vectors expressing drug-resistant or WT NAMPT. SCGs were left untreated or $100 \mathrm{nM}$ FK866 was added just after transection as indicated. (f) The percentage of fluorescent degenerated axons was calculated in 3-6 fields of three independent experiments as in panel (e). The results show that drug-resistant NAMPT ${ }^{\mathrm{G} 217 \mathrm{R}}$ expression restores rapid axon degeneration after FK866 treatment partially at $8 \mathrm{~h}$ and totally at $24 \mathrm{~h}$ after cut (mean \pm S.E.M., $n=6-18$, one-way ANOVA followed by Bonferroni's post-hoc test $\left.{ }^{\star} P<0.05,{ }^{* \star *} P<0.001\right)$. NS, not significant

broadly similar to that needed to kill axons (Figure $2 b$ ), considering the contribution of non-axonal material in the nerve and partial penetration of exogenous NMN. Simultaneously, NAD decreases (Figure 4A(b)). We saw no other gross change in the high-performance liquid chromatography (HPLC) profile (Supplementary Figure S8A), and using HPLC and mass spectrometry we also excluded a rise in NR (Supplementary Figure S8A(b and c) and B). Both NMN and NAD remained stable in lesioned Wld ${ }^{S}$ nerves (Figure 4B).
These data support the notion that NMNAT2 rapidly degrades in injured axons and that $\mathrm{WId}^{\mathrm{S}}$ directly substitutes for it when present. ${ }^{16,19}$ The early rise in NMN suggests that NMNAT2 is depleted after axotomy in vivo as well as in primary culture, ${ }^{16,19}$ although possibly less quickly consistent with the slower onset of Wallerian degeneration in vivo. We also found that whole brains of embryos lacking NMNAT2 (which die perinatally with severely truncated peripheral nerves) also show raised NMN levels (Figure 4C(a)). Crucially, these 

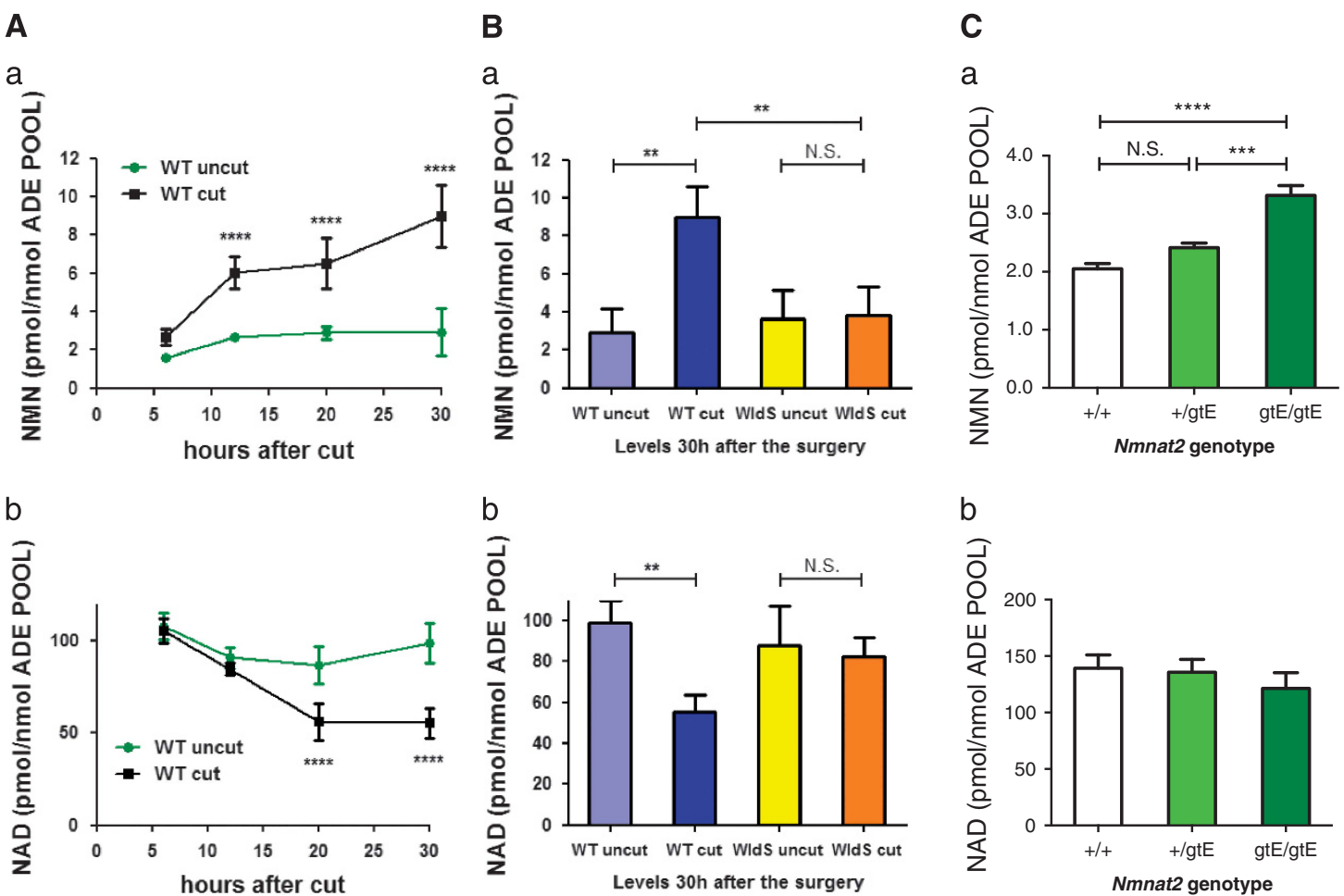

Figure 4 NMN accumulates in injured sciatic nerves before degeneration. (A) NMN (a) and NAD (b) levels were determined in mouse sciatic nerves at the indicated time points after nerve transection, and in the contralateral uncut nerve, and normalized to the total adenylate pool (ATP+ADP $+A M P)$ as a measure of nucleotide yield $(n=4$ per time point; mean \pm S.E.M., two-way ANOVA with Bonferroni's post-hoc test, $\left.{ }^{* * *} P<0.0001\right)$. Minor changes in the unlesioned, contralateral nerves likely reflect that they are not completely isolated from the effects of the operation such as anaesthesia and secondary effects. (B) NMN (a) and NAD (b) levels in sciatic nerves lesioned for $30 \mathrm{~h}$ of WT and WId $^{S}$ mice $\left(n=3-4\right.$, one-way ANOVA with Bonferroni's post-hoc test, $\left.{ }^{* \star} P<0.01\right)$. (C) NMN (a) and NAD (b) levels were determined in the whole brain of WT E18.5 embryos $(+/+)$ and of E18.5 embryos of heterozygous ( $+/ \mathrm{gtE}$ ) or homozygous ( $\mathrm{gtE} / \mathrm{gtE}$ ) for the Nmnat $2^{\mathrm{gtE}}$ allele from which NMNAT2 expression is non-detectable. ${ }^{18}$ There is a clear increase in NMN levels in homozygous mice that do not express any NMNAT2 $\left(n=5\right.$, one-way ANOVA with Tukey's post-hoc test, $\left.{ }^{* \star \star} P<0.001,{ }^{* \star \star \star} P<0.0001\right)$

measurements may underestimate the increase in axons, where the consequences of the lack of NMNAT2 are most evident; indeed, axons in many parts of the brains of mice lacking NMNAT2 are additionally likely to be severely stunted due to an underlying outgrowth defect. ${ }^{18}$ This might also explain why there is no significant reduction in NAD levels in the whole brains of these mice (Figure $4 \mathrm{C}(\mathrm{b})$ ).

Intriguingly, ATP and energy charge remain remarkably constant in injured sciatic nerves during the latent phase of degeneration (Supplementary Figure S8A), so axons in vivo do not undergo an early bioenergetic deficit. Finally, for a first indication of where NMN may act, subcellular fractionation experiments showed that NMN concentrations in cytosol $30 \mathrm{~h}$ post-lesion were much higher than in any other compartment, in contrast to a previous study where cytosol had the lowest NMN level in two cell lines, ${ }^{41}$ and consistent with the cytosolic location of NAMPT and cytoplasmic location of NMNAT2 (Supplementary Figure S8B). However, the possibility of an NMN increase, especially highly localized, also in other subcellular compartments cannot be completely ruled out. We also cannot completely exclude a rise in NMN in Schwann cells. However, axons are known to lose both NMNAT and its product NAD after axotomy, ${ }^{16,26}$ and this would likely be accompanied by a rise in axonal NMN, as NAMPT is stable and can continue to synthesize NMN (Supplementary Figures S3E and F). In contrast, there is neither data nor a rationale at present to suggest such a change in Schwann cells. Thus
NMN accumulates in the cytosol prior to axon degeneration, and although NAD also declines, there is no concomitant reduction in ATP.

FK866 prevents NMN accumulation in injured nerves and preserves functional axons and neuromuscular synapses. We confirmed that FK866 blocks the rise in NMN using explanted nerves cultured for $30 \mathrm{~h}$. Explanting nerves necessarily involves axotomy, and we previously showed that this system discriminates the WId ${ }^{S}$ and WT phenotypes. ${ }^{40}$ Similar to in vivo, NMN rose in these nerves while both NMN and NAD were significantly depleted after treatment with $10 \mu \mathrm{M}$ FK866 (Figure 5A(a)). The higher concentration required to achieve this reflects the thickness of the nerve and the presence of abundant myelin. We found that axons in cultured FK866-treated yellow fluorescent protein (YFP-H) nerves ${ }^{40}$ fragmented significantly later than vehicle-treated nerves (Figures $5 \mathrm{~A}(\mathrm{~b})$ ).

To test whether these axons remain functional and whether neuromuscular synapses can also be preserved, we isolated nerve-muscle preparations of flexor digitorum brevis (FDB) and cultured them overnight in oxygenated mammalian Ringer's solution, with or without FK866 (1 and $10 \mu \mathrm{M})$. Wildtype muscle fibres lose both evoked and spontaneous miniature end-plate potentials (mEPPs) during overnight incubation, whereas $\mathrm{WId}^{\mathrm{S}}$ prevents this loss and preserves excitability and competence to release the neurotransmitter 
A

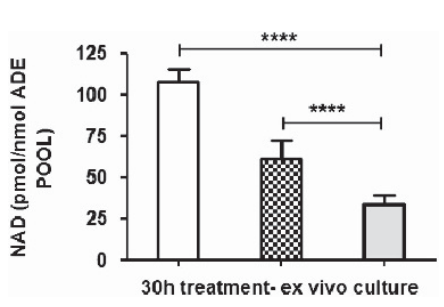

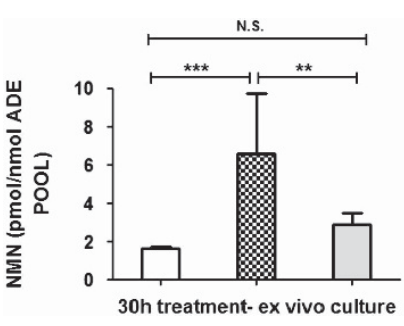

b

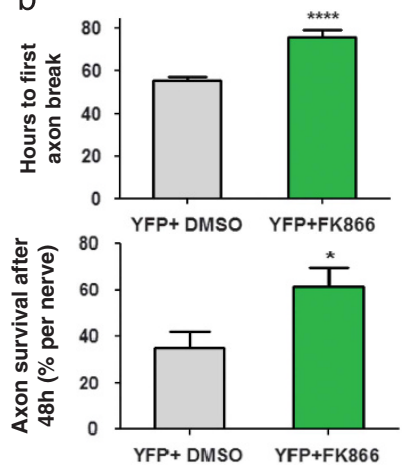

B

a

\begin{tabular}{|c|c|}
\hline & $\begin{array}{c}\% \text { fibres } \\
\text { showing EPPs } \\
\text { and/or MEPPs }\end{array}$ \\
\hline WT & 24.10 \\
\hline Het WId ${ }^{S}$ & 24.58 \\
\hline WId $^{\mathrm{s}}$ & 99.07 \\
\hline$W T+1 \mu M$ FK866 & 49.58 \\
\hline WT $+10 \mu M$ FK866 & 69.24 \\
\hline$W_{1 d}{ }^{S}+1 \mu M$ FK866 & 100.00 \\
\hline
\end{tabular}

b

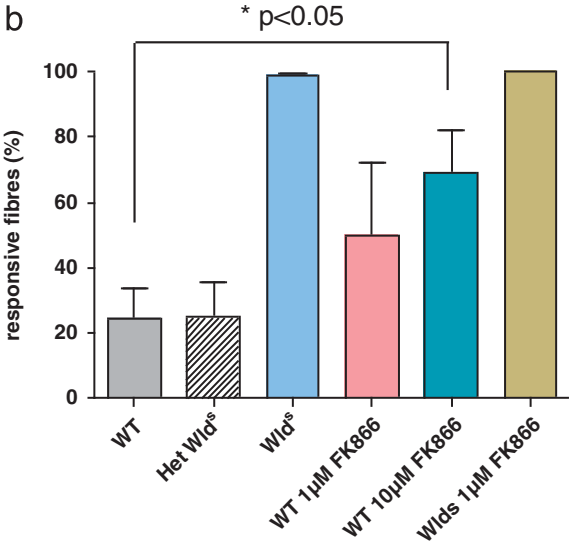

C

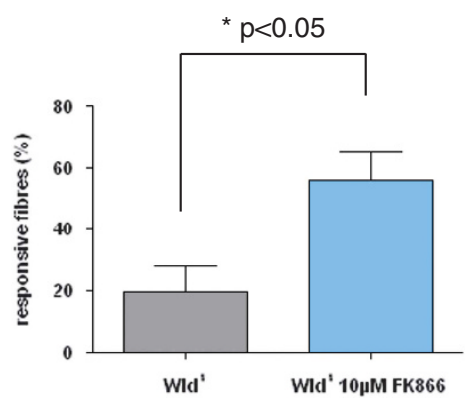

Figure 5 FK866 is effective ex vivo and preserves functional axons and neuromuscular synapses. (A) FK866 delays Wallerian degeneration ex vivo. (a) NAD (left panel) and NMN (right panel) levels were determined in mouse sciatic nerve explants cultured for $30 \mathrm{~h}$ in the presence of $10 \mu \mathrm{M} \mathrm{FK866} \mathrm{or} \mathrm{vehicle} \mathrm{(DMSO)} \mathrm{and} \mathrm{normalized} \mathrm{against} \mathrm{the} \mathrm{total}$ adenylate pool ( $n=10$, mean \pm S.E.M., unpaired Student's $t$-test, $\left.{ }^{* *} P<0.01,{ }^{* \star} P<0.001,{ }^{* * \star *} P<0.0001\right)$. (b) Rate of axon degeneration in YFP-H nerve explants cultured for $135 \mathrm{~h}$ in the presence of $10 \mu \mathrm{M}$ FK866 or DMSO control. The upper panel shows the time until the first axon break appeared in each nerve. The lower panel shows the percentage of surviving axons in each nerve after $48 \mathrm{~h}\left(n=5-10\right.$ nerves; mean \pm S.E.M., one-way ANOVA with Bonferroni's post-hoc test, ${ }^{*} P<0.05$, $\left.{ }^{* * * *} P<0.0001\right)$. (B) FK866 applied to WT muscles mimics synaptic protection conferred by WId ${ }^{S}$ ex vivo. The number of responsive fibres, that is, those showing EPPs upon stimulation and/or spontaneous miniature EPPs, was analysed in isolated tibial nerve/FDB muscle preparations that had been incubated in MPS containing FK866 in panels (a and b) for 16-20 $\mathrm{h}(n=4-5 \mathrm{muscles}$ in each group) and in panel (c) for 42-48 $\mathrm{h}$ ( $n=8$ muscles in both groups). FK866 dose-dependently delayed synaptic degeneration in WT muscles at 16-20 $\mathrm{h}(P<0.05$; ANOVA with post-hoc Dunnett's test) and potentiated the protective effect of $W / d^{\delta}$ at $48 \mathrm{~h}\left(P<0.05 ;\right.$ t-test). Note that synaptic degeneration in FDB muscles from WId ${ }^{\delta}$ mice was markedly more rapid ex vivo than in vivo, ${ }^{64}$ probably reflecting the shorter nerve stump length and altered environment. However, the phenotype is readily distinguished from WT ex vivo, with incubation in MPS at $32^{\circ} \mathrm{C}$. het $=$ heterozygous

(Figure 5B). FK866 showed a dose-dependent protection on WT fibres at 16-20 $\mathrm{h}$ that became statistically significant at $10 \mu \mathrm{M}$ (Figures 5B(a) and (b)). FK866 also potentiated WId ${ }^{\mathrm{S}}$ protective capacity at $42-48 \mathrm{~h}$ (Figure $5 \mathrm{~B}(\mathrm{c})$ ). Thus FK866 maintains structural and functional integrity of both the distal axon stump and the neuromuscular junction.

FK866 delays Wallerian degeneration in vivo. To assess FK866 protection in vivo, we treated zebrafish larvae 48-54 h postfertilization, transiently expressing DsRed-Express in trigeminal and Rohon-Beard somatosensory neurons (Figure 6a), with FK866 for $2 \mathrm{~h}$ prior to two-photon laser axotomy. FK866 delayed degeneration of zebrafish sensory axons dose-dependently, up to a five-fold, similar to in vitro (Figures $6 \mathrm{~b}$ and $\mathrm{c}$ and Supplementary Videos S1 and S2). Interestingly, degeneration was synchronous for axonal branches in vehicle-treated fish but asynchronous with FK866, such that around $20 \%$ of branches survived eightfold longer than normal (Figures $6 b-c)$. To determine whether escalating doses of FK866 cause axon or neuronal toxicity in vivo, we treated fish with $1 \mathrm{mM}$ FK866 and found a decrease in the potency of protection but no cell death or axon regeneration defects during $12-20 \mathrm{~h}$ of imaging.

These results demonstrate that treatment with NAMPT inhibitor FK866 potently delays axonal degeneration in vivo in a vertebrate model organism.

\section{Discussion}

The ability of $\mathrm{Wld}^{\mathrm{S}}$, an NMNAT1 fusion protein, to delay axon degeneration ${ }^{10}$ has led to the widely held assumption that NAD synthesis is central to its neuroprotective mechanism. ${ }^{25,26}$ In contrast, our data show that NMNATsubstrate NMN accumulates before injured nerves degenerate, that exogenous NMN promotes axon degeneration when NMNAT is absent and that scavenging NMN delays degeneration. To our knowledge, NMN has no previously known function in mammals other than as an NAD precursor.

Considerable NAD depletion causes no overt harm to axons within the timescale of Wallerian degeneration. Instead, 
a

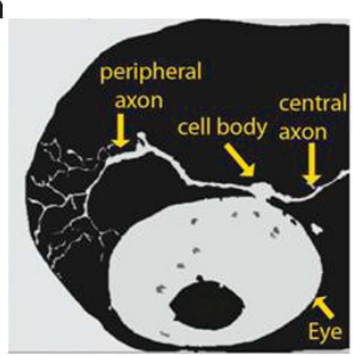

b

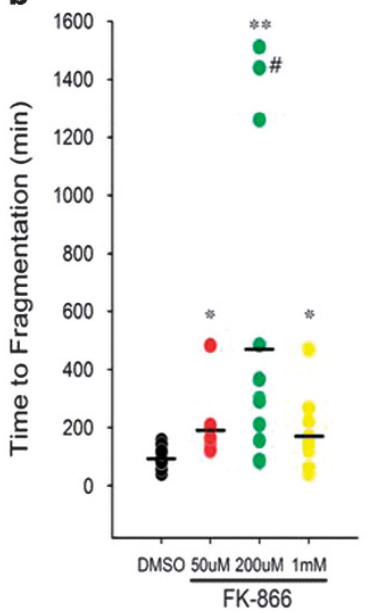

C
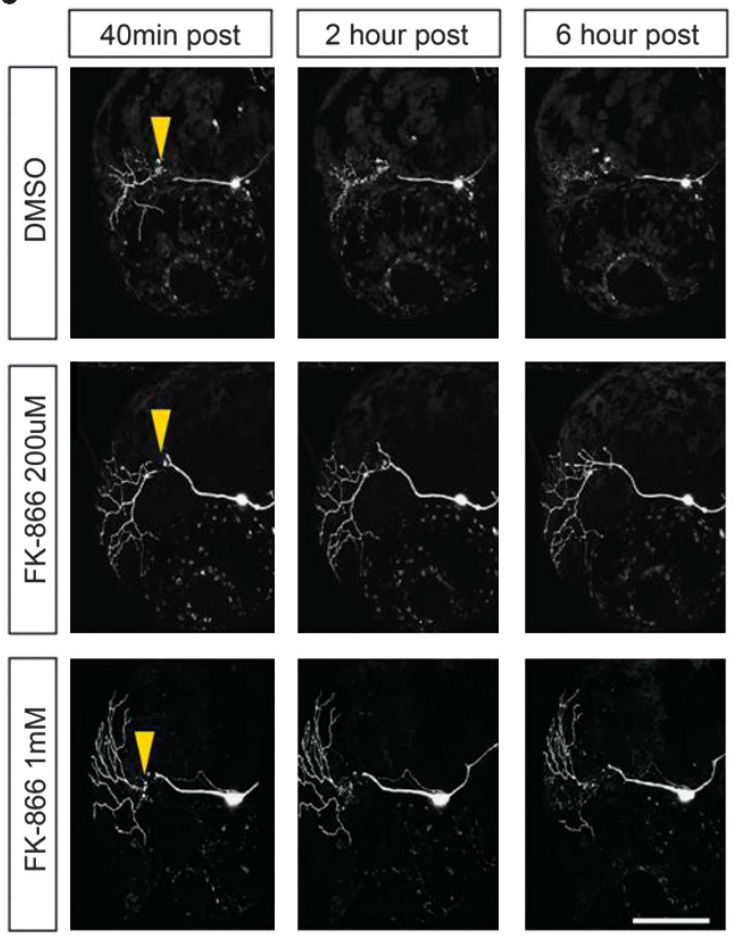

Figure 6 FK866 delays Wallerian degeneration in vivo. (a) Schematic of larval zebrafish head indicating position of trigeminal neurons and axons, relative to the fish eye. (b) Time to beginning of fragmentation following laser axotomy in larvae pretreated for $2 \mathrm{~h}$ with vehicle (1\% DMSO) $(n=25), 50 \mu \mathrm{M}(n=9), 200 \mu \mathrm{M}(n=11)$ or $1 \mathrm{mM}(n=10)$ FK866. Each circle represents one experiment; horizontal bar denotes average degeneration time (\# indicates data from axon still intact $>24 \mathrm{~h},{ }^{\star} P<0.05 ;{ }^{* \star} P<0.001$ ). (c) Confocal images of trigeminal neurons postaxotomy labeled with DsRed-Express and treated with 1\% DMSO or FK866. Arrowheads point to the site of axotomy. Scale bar, $100 \mu \mathrm{m}$

consistent with the rapid degradation of endogenous NMNAT2, ${ }^{16,19}$ a rise in NMN is detectable within $12 \mathrm{~h}$ of nerve lesion, $24 \mathrm{~h}$ before the first axons degenerate. ${ }^{40}$ Stable ATP levels indicate that there is no bioenergetic deficit by $30 \mathrm{~h}$, shortly before axons degenerate. ${ }^{40}$ The suggestions that a bioenergetic imbalance initiates axon and synaptic dysfunction ${ }^{42,43}$ and that FK866 protects axons by maintaining ATP $^{44,45}$ are difficult to fit with this observation.

Instead, our data strongly suggest that FK866 prolongs the functional survival of transected axons and their synapses in vitro, ex vivo and in vivo and delays neurite degeneration induced by vincristine, by blocking a rise in NMN. Three independent methods to prevent NMN accumulation delay Wallerian degeneration: sequestering with $\mathrm{Wld}^{\mathrm{S}}$, blocking synthesis by NAMPT inhibition, or deamidating with ectopically expressed bacterial NMN deamidase. We cannot completely exclude a role for a related, potentially even unknown, endogenous metabolite of NMN, but there is no detectable rise in NR. Similarly, we cannot completely rule out any off-target or additional effects of FK866, even on neuromuscular junctions, although the high specificity of FK866 and our genetic evidence make it unlikely as a mechanism of protection from Wallerian degeneration. We conclude that a rise in NMN is necessary for Wallerian degeneration and its exogenous delivery promotes degeneration when there is no enzyme to remove it.
In other cellular circumstances, NMN can have cytoprotective properties, ${ }^{46-49}$ making our findings particularly unexpected. However, all cells and tissues in those studies contained NMNAT to convert NMN into NAD and cytoprotection reflects NAD production not NMN itself. The effect of NMN on glucose tolerance was accompanied by an NMN peak 15 min after systemic administration, before falling back to normal levels as NAD rose, ${ }^{48}$ and in ischemic models exogenous NAD was also protective. ${ }^{46}$ In contrast, lesioned nerves have insufficient NMNAT to metabolize NMN. Hence, its levels rise continually for $>30 \mathrm{~h}$, eventually reaching a threshold that we propose activates downstream degenerative events. In contrast, NAD falls (Figures 4 and 5). Several studies report beneficial effects of NAD or its precursors in axonal or neuronal degeneration models but in these NMNAT was still present when these compounds were administered. Here, in contrast, we add NMN up to $12 \mathrm{~h}$ after axotomy (Figure 2d) when NMNAT is degraded. We suggest this underlies the different effect we observe.

Downstream of NMN, possible mechanisms include direct actions on an essential protein or a signal activating an axon degeneration program. For example, myeloid differentiation factor 88-5/sterile alpha and TIR motif-containing protein 1 (MyD88-5/SARM1) is required for axotomy-induced axon degeneration, ${ }^{50}$ and membrane occupation and recognition nexus repeat containing 4 (MORN4) is required for 
Taxol-induced degeneration. ${ }^{51}$ Due to structural homology, inhibition of NAD-dependent enzymes by NMN is another possibility, although NAD remains in a high molar excess over NMN. We found no effect on four dehydrogenases (inosine monophosphate dehydrogenase, glycerol-3P dehydrogenase, L-glutamate dehydrogenase, malic dehydrogenase), although we cannot rule out an effect on other NADdependent proteins, similar to inhibition of NAD-dependent DNA ligase in bacteria. Alternatively, excess cytoplasmic NMN may interfere with poorly understood mechanisms that exchange pyridine nucleotides between mitochondria and cytoplasm, ${ }^{33}$ potentially leading to mitochondrial dysfunctions. ${ }^{23,24}$

Wld $^{S}$ and other NMNATs protect through a gain of function, ${ }^{52}$ so moving this towards translation has been challenging. Here, by investigating the action of $\mathrm{Wld}^{\mathrm{S}}$, we observed that FK866 and CHS-828, two drugs already in human clinical trials for cancer, are axon protective. ${ }^{29,53} \mathrm{We}$ confirm significant protection of neuromuscular synapses, potentiation of Wld ${ }^{\mathrm{S}}$ phenotype in organotypic nerve/muscle explants and prevention of Vincristine-induced axon damage in primary culture. Importantly, FK866 protection in the absence of general toxicity is observed also in vivo. The marked contrast between axon preservation by FK866 and CHS-828 and the dose-limiting peripheral neuropathy caused by many existing cancer therapeutic ${ }^{54}$ suggests that combination therapies could simultaneously enhance chemotherapy and reduce neuropathy. FK866 was well tolerated in phase I trials and has shown some effect in cases of cutaneous T-cell lymphoma (http://www.clinicaltrials.gov), opening the prospect of its combinatorial use with compounds reported to cause peripheral neuropathy such as platinum compounds, vinka alkaloids, taxol or more recent chemotherapeutics (e.g., methotrexate, etoposide and $\mathrm{AraC}$ ), although toxicity from long-term NAD depletion could arise.

In summary, we identify a key role for NMN accumulation in promoting Wallerian degeneration and reveal NMNsynthesising enzyme NAMPT as an important new therapeutic target in axonopathies. Remarkably, NMN starts rising long before axons fragment, suggesting ample time for downstream events. Our results tie an NMN increase to axon degeneration, suggesting it could be the long hypothesized 'deleterious factor ${ }^{55}$ and key player in the active mechanism of axon degeneration. ${ }^{56,57}$ They identify pharmacological agents that delay axon degeneration and suggest an important potential for combinatorial cancer treatments.

\section{Materials and Methods}

Plasmids. Murine NAMPT was generated by amplification of the full coding region by reverse transcriptase-PCR (RT-PCR) (see below) from $1 \mu \mathrm{g}$ total mouse brain RNA and cloned in pcDNA3.1(+) (Invitrogen, Paisley, UK). Inhibitor-resistant murine NAMPT ${ }^{\text {G217R }}$ was obtained from WT NAMPT in pcDNA3.1(+) by sitedirected mutagenesis using the QuikChange site-directed mutagenesis kit (Agilent STRATAGENE, Stockport, UK), following the manufacture's instructions, using the following primer: $5^{\prime}$-TGGTTAACTTTAAAAGAACAGCAGATACTGTGGC-3' and its reverse complementary. E. coli (Uniprot ID: POA6G3) NMN deamidase (WT, Mut1 and Mut2) open reading frame (ORF) was amplified by PCR from bacterial expression plasmids ${ }^{39}$ (kind gift of Professor Nadia Raffaelli) using primers carrying Bglll and Hindlll restriction overhangs for directional cloning into pEGFP-C1 vector (BD Biosciences Clontech, Saint-Germain-en-Laye, France) (primer sequence: For: 5'-GGAAGATCTACTGACAGTGAACTGATG-3' and Rev: 5'-GCTGAAGCTTCTAAG
TGTTTTGTAGAAATTG-3'). S. oneidensis (Uniprot ID: Q8EK32) NMN deamidase ORF was subcloned from a bacterial expression plasmid ${ }^{39}$ (kind gift of Professor Nadia Raffaelli) into pCDNA3.1/HISA vector (Invitrogen) using BamHI/Notl restriction enzymes. The resulting plasmids were replicated in DH5-alpha and sequence verified (Beckman Coulter, High Wycombe, UK).

Other plasmids used were pDsRed2-N1 for expression of variant Discosoma red fluorescent protein (DsRed2) and pEGFP-C1 for expression of eGFP (both BD Biosciences Clontech).

RT-PCR. RT-PCR from total brain RNA was performed as described ${ }^{16}$ using the following primer pair to amplify murine NAMPT: $5^{\prime}$-CGGCCCGAGATGAATGCTGC-3' and 5'-CTAATGAGGTGCCACGTCCTGCT -3'.

Mouse origin and genotyping. C57BL/6 WT mice were obtained by Charles River (Saffron Walden, UK). YFP-H mice ${ }^{58}$ were obtained from The Jackson's Laboratory (Bar Harbor, ME, USA) and genotyped by Southern blotting (YFP probe generated by PCR from YFP-H mouse genomic DNA using the primers 5'-CGAACTCCAGCAGGACCATGTGAT-3' and 5'-CTTCTTCAAGGACGACGGCAA CTACAAG- $\left.3^{\prime}\right)$.

All animal work was performed in accordance with the 1986 Animals (Scientific Procedures) Act under project licences PPL 80/1778, PPL 80/2254 and PPL 40/3482.

Nerve lesions. Sciatic nerve lesions were performed as previously described. ${ }^{27}$ Right sciatic nerves were transected at the upper thigh and wounds closed with sutures. After $6-30 \mathrm{~h}$, mice were killed by cervical dislocation, and the swollen first $2 \mathrm{~mm}$ of distal nerve was discarded. The remaining distal sciatic nerve stump was used for nucleotide content determination or for imaging of axon degeneration.

Subcellular fractionation. Sciatic nerves from WT mice were dissected as described above and processed either immediately or after $30 \mathrm{~h}$ ex vivo culture. Nerves were homogenized in buffer containing $0.22 \mathrm{M}$ mannitol, $70 \mathrm{mM}$ sucrose, $10 \mathrm{mM}$ Tris pH7.4, 0.5 mM EDTA and protease inhibitor cocktail. The homogenate was then centrifuged at $4{ }^{\circ} \mathrm{C}$ at $800 \times \mathrm{g} / 10 \mathrm{~min}$ to eliminate cell debris and nuclei, and the supernatant further was centrifuged at $12000 \times \mathrm{g} / 20 \mathrm{~min}$ to separate the mitochondrial pellet from the supernatant containing cytosol and non-mitochondrial membranes. Pellets and supernatant were rapidly frozen and analysed by HPLC or Mass Spectrometry-based determination of NMN and NAD levels.

Sciatic nerve explant culture. Unlesioned sciatic nerves from YFP-H or WT mice killed by cervical dislocation were quickly removed and transferred into a sterile dish containing cold Hanks Buffered Saline Solution (PAA, Yevil Sommerst, UK). The non-neuronal tissue was removed under a dissection microscope, and nerves were cultured in Opti-MEM supplemented with $1 \%$ penicillin/streptomycin and with glutamax (both Invitrogen) in a humid atmosphere at $30{ }^{\circ} \mathrm{C}, 5 \% \mathrm{CO}_{2}$ for the times specified, as previously described. ${ }^{40}$ The nerves were forced down using insect pins placed onto a sterile $3-\mathrm{cm}$ dish previously coated with Sylgard (Dupont, Retford, UK) (for future HPLC analysis) or placed directly into an uncoated dish using a microscope chamber. FK866 (kind gift of Professor Armando Genazzani) $10 \mu \mathrm{M}$ or dimethyl sulfoxide (DMSO) were added to the explants at the beginning of the cultures and replaced every $24 \mathrm{~h}$. The degeneration was assessed using an inverted Olympus microscope (Olympus, Southend-on-Sea, UK) to visualize the direct YFP fluorescence. Some nerves were rapidly frozen after $30 \mathrm{~h}$ in culture for HPLC-based determination of NMN and NAD levels.

Explant or dissociated cell cultures and treatment. SCG and DRG explants were dissected and cultured, and axons were transected as previously described. ${ }^{59}$ Neurites were allowed to extend for 5-7 days in all cultures before cut. All compounds were from Sigma-Aldrich (Dorset, UK) unless otherwise stated. In the Vincristine experiments, this was used at a $0.02-\mu \mathrm{M}$ final concentration, and the day of treatment was considered time 0 . When FK866 and CHS-828 (synthesized at the Babraham Institute by Dr. Jonathan Clark) were used, the appropriate concentration of the drug was applied 16-20 h before cut, at the same time of cut or of Vincristine treatment or at 2-6 h after cut. When used, all nucleotides were added at the time of cut at $1 \mathrm{mM}$ unless otherwise indicated in the text. Axon degeneration was followed during time for up to another $72 \mathrm{~h}$. Degeneration index was calculated as described. ${ }^{28}$ To determine NAD levels, SCG and DRG explants were cultured for 7 days before FK866 treatment. At the established time points, SCG explants were collected and processed as described below. For some cultures, neurites were separated from their cell bodies by cutting around the explant with a scalpel, and 
cell body and neurite fractions were collected separately, washed in phosphatebuffered saline (PBS) and processed as described below. For some experiments and for microinjections, SCG explants were dissociated in single SCG neurons and cultured as described. ${ }^{16}$

Microinjection. Microinjection was performed as previously described ${ }^{16}$ with minor modifications. Dissociated cells were microinjected using a Zeiss Axiovert S100 microscope (Cambridge, UK) with an Eppendorf FemtoJet transjector and 5171 micromanipulator system and Eppendorf Femtotips (Stevenage, UK). Plasmids were diluted in $0.5 \times$ PBS to a concentration of $100 \mathrm{ng} / \mu$ l and passed through a Spin-X filter (Costar, Fisher, Loughborough, UK). The mix was injected directly into the nuclei of SCG neurons in dissociated cultures. All plasmids were co-injected with DsRed2 at a concentration of $25 \mathrm{ng} / \mu \mathrm{l}$. In all, 70-200 neurons were injected per dish. Injection of relatively few neurons per dish facilitated visualization of individual labelled neurites, as neurites tend to cluster together in bundles.

Acquisition and processing of images. Bright field images were acquired on an IX8I (Olympus) coupled to a digital camera (U-TV 0.5XC; Olympus) using the AnalySIS software (Soft Imaging System, GmbH, Southend-on-Sea, UK) or on an Observer Z1 (Zeiss, Cambridge, UK) microscope coupled to an EMCCD (Photometrics PVCam, Marlow, UK) camera using the Axiovision software (Carl Zeiss Inc., Cambridge, UK). The objectives used were UPlanFI $4 \times \mathrm{NA} 0.13$, LCPlanFI $20 \times$ NA 0.40 (all air objectives) and Zeiss EC Plan Neoflur $20 \times 0.5 \mathrm{NA}$ objectives. Fluorescent images were acquired using Observer Z1 (Zeiss) microscope coupled to an EMCCD (Photometrics PVCam) camera using the Axiovision software (Carl Zeiss Inc.). The fluorophores used were GFP and DsRed2. Images were acquired at $37^{\circ} \mathrm{C}$ or room temperature.

HEK293T and PC12 culture and transfection. HEK293T and PC12 cells were cultured under standard conditions in the following media: Dulbecco's modified eagle's medium (DMEM) with $4500 \mathrm{mg} / \mathrm{l}$ glucose and $110 \mathrm{mg} / \mathrm{l}$ sodium piruvate (PAA) supplemented with $2 \mathrm{mM}$ glutamine, $1 \%$ penicillin/streptomycin (both Invitrogen) and 10\% foetal bovine serum (PAA) for HEK293T cells; DMEM with $4500 \mathrm{mg} / \mathrm{l}$ glucose and $110 \mathrm{mg} / \mathrm{l}$ sodium piruvate (Sigma, Dorset, UK) supplemented with $2 \mathrm{mM}$ glutamine, $1 \%$ penicillin/streptomycin (both Invitrogen) and $5 \%$ foetal bovine serum (PAA) and 10\% horse serum (Invitrogen) for PC12 cells. For transfection, cells were plated so that they reached $60-80 \%$ confluence on the day of transfection and were transfected using Lipofectamine 2000 reagent (Invitrogen). Cells in a 24-well dish format were transfected with $800 \mathrm{ng} /$ well of the plasmids. Cells were collected $48-72 \mathrm{~h}$ after transfection.

Western blotting. Western blotting of cell body or neurite homogenates were performed as described previously. ${ }^{27}$ In addition to NAMPT (1:2000, Enzo Life Sciences, Exeter, UK), mouse monoclonal anti-histone $\mathrm{H} 1$ (1:500; Millipore, Nottingham, UK), and mouse monoclonal anti $\beta$-actin (1:5000; Abcam, Cambridge, UK) were used as loading controls for the cell body and the neurite fraction, respectively. For quantification, western blotting for NMNAT2 $(2.0 \mu \mathrm{g} / \mathrm{ml}$, Abcam) was performed as described in. ${ }^{16}$ Western blotting band intensities were determined and analysed with the ImageJ software (National Institutes of Health, Bethesda, MD, USA). Western blotting of HEK293T or PC12 cell homogenates were performed as described, ${ }^{27}$ and blots were probed with an anti-his antibody (Sigma, H1029).

Determination of nucleotide levels. To determine NAD levels, SCG and DRG explants or cells cultured, treated and collected as described above were lysed by resuspension in water and by passing through a syringe needle. Cell lysates were first acidified and then neutralized by adding $\mathrm{HClO}_{4}$ and $\mathrm{K}_{2} \mathrm{CO}_{3}$, respectively, and finally loaded on LC18 Supelcosil column (Sigma-Aldrich). ${ }^{60}$

For determination of NMN, NAD and other nucleotides content, whole brains of WT, E18.5 embryos or E18.5 embryos heterozygous or homozygous for the Nmnat $2^{\text {gte }}$ allele ${ }^{18}$ or alternatively dissected sciatic nerves or sciatic nerve explants were rapidly frozen in liquid nitrogen and stored at $-80^{\circ} \mathrm{C}$ until processed. Then, $\mathrm{N}_{2}$-ground tissue aliquots were extracted in $\mathrm{HClO}_{4}$ by sonication and neutralized by adding $\mathrm{K}_{2} \mathrm{HPO}_{4}$. Finally, NAD was measured by UV-C18-HPLC and referred to the total adenylate pool (=adenosine monophosphate+adenosine diphosphate+ATP) extracted. In each extract, NMN was instead measured upon derivatization with acetophenone and spectrofluorometric HPLC analysis, carried out as described, ${ }^{41}$ by using a duplicate sample analysed in parallel containing NMN spike of a known amount. Nucleotide levels in subcellular fractions were determined by liquid chromatography electrospray ionization-tandem mass spectrometry.

Determination of NMN deamidase activity. HEK and PC12 cells transfected with the empty vector or $S$. oneidensis or E. coli NMN deamidase (WT and mutant) expressing vectors were lysed by sonication in $50 \mathrm{mM}$ Tris $\mathrm{HCl}$, $150 \mathrm{mM} \mathrm{NaCl}, 1 \mathrm{mM}$ DTT and protease inhibitors. NMN deamidase activity was measured by coupling NaMN formation to its adenylation to NaAD by the bacterial enzyme NaMN adenylyltransferase (NadD, kind gift of Professor Nadia Raffaelli), which is strictly specific for the deamidated form of the mononucleotide. The reaction mixtures contained $100 \mathrm{mM}$ potassium phosphate buffer $\mathrm{pH} 8,10 \mathrm{mM} \mathrm{NaF}$, $10 \mathrm{mM} \mathrm{MgCl}_{2}, 1.6 \mathrm{mM}$ ATP, $0.1 \mathrm{mM}$ NMN, 10 mUnits recombinant NadD from $E$. coli and cell lysates. After 30 min incubation at $37^{\circ} \mathrm{C}$, the formed $\mathrm{NaAD}$ was quantified by an HPLC-based method. ${ }^{60}$

Electrophysiological assay of synaptic degeneration ex vivo. Mice were killed by cervical dislocation. Tibial nerve/FDB muscle preparations were dissected and pinned onto small strips of cured Sylgard resin. These were then placed in sterile $20 \mathrm{ml}$ tubes containing filtered MPS mammalian physiological saline (MPS; $120 \mathrm{mM} \mathrm{NaCl}, 5 \mathrm{mM} \mathrm{KCl}, 2 \mathrm{mM} \mathrm{CaCl}, 1 \mathrm{mM} \mathrm{MgCl}$, $0.4 \mathrm{mM} \mathrm{NaH}_{2} \mathrm{PO}_{4}, 23.8 \mathrm{mM} \mathrm{NaHCO}_{3}, 5.6 \mathrm{mM}$ Glucose) equilibrated with $95 \% \mathrm{O}_{2}$, $5 \% \mathrm{CO}_{2}$. The preparations were maintained at $32{ }^{\circ} \mathrm{C}$ in a water bath for up to $48 \mathrm{~h}$. Preliminary investigations established that, at this time, the amount of synaptic degeneration in muscles from WId ${ }^{S}$ and WT mice were readily distinguished. FK866 (1-10 $\mu \mathrm{M})$ was added to the bathing medium. The muscles were bubbled in fresh MPS for $20 \mathrm{~min}$ at room temperature prior to electrophysiological estimation of the number of innervated muscle fibres. Intracellular recordings were made using standard microelectrode techniques as described previously. 61,62 The WinWCP (Strathclyde Electrophysiological Software, Glasgow, UK) and MiniAnalysis (Synaptosoft, Atlanta, GA, USA) softwares were used for EPP and mEPP ${ }^{61}$ recording and analysis.

Assessment of Wallerian degeneration in zebrafish larvae. To obtain mosaic labelling of somatosensory neurons, $10 \mathrm{pg}$ of the plasmid CREST3: LexA, LexAop:DsRed-Express N1 was injected into one-cell stage embryos. Larvae were anaesthetized in $0.01 \%$ tricaine and mounted in $1 \%$ low melt agarose, and two-photon laser axotomy was carried out as previously described. ${ }^{63}$ Time-lapse images were obtained at 20-25 min intervals from 12 to $20 \mathrm{~h}$ using a Zeiss LSM 510 confocal microscope. Larvae were kept at $28.5^{\circ} \mathrm{C}$ during the imaging period. Fish were pretreated with FK866 in DMSO/pluronic or with vehicle alone $2 \mathrm{~h}$ before axotomy.

Statistical analysis. Data were analyzed with Prism5 (Graph Pad) using ANOVA (analysis of variance) and Student's $t$-tests, with $P$-values of $<0.05$ being considered significant for any set of data.

\section{Conflict of Interest}

LC and MPC are inventors on a patent application filed by the Babraham Institute relating to this study. The remaining authors declare no conflict of interest.

Acknowledgements. We thank Professor Nadia Raffaelli for NMN deamidase constructs, NadD, helpful discussion and technical advice, Professor Armando Genazzani and the NIMH Chemical Synthesis and Drug Supply Program for kindly providing FK866, Dr. Jonathan Clark for synthesis of CHS828, Dr. Simon Cook for useful comments on the manuscript, Ms. Claire Harwell for technical assistance, Dr. Giacomo Morreale for helpful discussion, Tim Self for use of imaging facilities, David Tooth for help with HPLC determinations and Anne Segonds-Pichon for advice on statistical analysis. This work was funded by the Biotechnology and Biological Sciences Research Council Institute Strategic Programme Grant (to MPC, LC, INF), Alzheimer's Research UK grant ART/PG2009/2 (to LC, JP), a Faculty of Medicine and Health Sciences, University of Nottingham, nonclinical senior fellowship (to LC, MDS, WM, MM, FR), a grant from the National Institute of Dental and Craniofacial Research (1R01DE019487) to AS, a Marie Curie Intra European Fellowship within the 7th European Community Framework Program (to MDS, LC) and by the ERASMUS mobility program (AL). The funders had no role in study design, data collection and analysis, decision to publish or preparation of the manuscript. 


\section{Author contributions}

LC and MPC conceived and initiated the study; LC, MDS, INF, GO, LAW, RB and VM, designed and conducted most experiments, collected the data and conducted the analyses. LC and MDS performed most experiments on DRGs and SCGs, including the NMN deamidase work; most in vivo and ex vivo nerve experiments were conducted by INF with some input from MPC and LC, and nucleotide measurements from VM, FMC and GO; zebrafish experiments were conducted and analyzed by MEV and $\mathrm{AS}$; RB conducted all experiments on nerve-muscle preparations with some input from LC and RRR; JG, LJ, LAW, AL, JT, JP, JRMW, MM, SP, WM and FR performed some of the in vitro experiments. LC, GM, RRR and MPC supervised and coordinated the research. LC and MPC co-wrote the manuscript with additional input from MDS, INF, GO, MEV, AS, JG, RB and RRR.

1. Stoll G, Jander S, Myers RR. Degeneration and regeneration of the peripheral nervous system: from Augustus Waller's observations to neuroinflammation. J Peripher Nerv Syst 2002; 7: 13-27.

2. Lunn ER, Perry VH, Brown MC, Rosen H, Gordon S. Absence of Wallerian degeneration does not hinder regeneration in peripheral nerve. Eur J Neurosci 1989; 1: 27-33.

3. Conforti L, Gilley J, Coleman MP. Wallerian degeneration: an emerging axon death pathway linking injury and disease. Nat Rev Neurosci 2014; 15: 394-409.

4. Agostini M, Bedin C, Pucciarelli S, Enzo M, Briarava M, Seraglia R et al. APC I1307K mutations and forkhead box gene (FOXO1A): another piece of an interesting correlation. In J Biol Markers 2012; 27: 13-19.

5. Martin SM, O'Brien GS, Portera-Cailliau C, Sagasti A. Wallerian degeneration of zebrafish trigeminal axons in the skin is required for regeneration and developmental pruning. Development 2010; 137: 3985-3994.

6. Adalbert R, Gillingwater TH, Haley JE, Bridge K, Beirowski B, Berek L et al. A rat model of slow Wallerian degeneration (WIdS) with improved preservation of neuromuscular synapses. Eur J Neurosci 2005; 21: 271-277.

7. MacDonald JM, Beach MG, Porpiglia E, Sheehan AE, Watts RJ, Freeman MR et al. The Drosophila cell corpse engulfment receptor Draper mediates glial clearance of severed axons. Neuron 2006; 50: 869-881.

8. Kitay BM, McCormack R, Wang $Y$, Tsoulfas $P$, Zhai RG. Mislocalization of neuronal mitochondria reveals regulation of Wallerian degeneration and NMNAT/WLDS-mediated axon protection independent of axonal mitochondria. Hum Mol Genet 2013; 22 1601-1614

9. Conforti L, Tarlton A, Mack TG, Mi W, Buckmaster EA, Wagner D et al. A Ufd2/D4Cole1e chimeric protein and overexpression of Rbp7 in the slow Wallerian degeneration (WIdS) mouse. Proc Natl Acad Sci USA 2000; 97: 11377-11382.

10. Mack TG, Reiner M, Beirowski B, Mi W, Emanuelli M, Wagner D et al. Wallerian degeneration of injured axons and synapses is delayed by a Ube4b/Nmnat chimeric gene. Nat Neurosci 2001; 4: 1199-1206.

11. Koch-Nolte F, Fischer S, Haag F, Ziegler M. Compartmentation of NAD+-dependent signalling. FEBS Lett 2011; 585: 1651-1656.

12. Berger F, Lau C, Dahlmann M, Ziegler M. Subcellular compartmentation and differential catalytic properties of the three human nicotinamide mononucleotide adenylyltransferase isoforms. J Biol Chem 2005; 280: 36334-36341.

13. Conforti L, Wilbrey A, Morreale G, Janeckova L, Beirowski B, Adalbert R et al. WId S protein requires Nmnat activity and a short $\mathrm{N}$-terminal sequence to protect axons in mice. J Cell Biol 2009; 184: 491-500.

14. Beirowski B, Babetto E, Gilley J, Mazzola F, Conforti L, Janeckova L et al. Non-nuclear Wld (S) determines its neuroprotective efficacy for axons and synapses in vivo. J Neurosci 2009; 29: 653-668.

15. Avery MA, Sheehan AE, Kerr KS, Wang J, Freeman MR. WId S requires Nmnat1 enzymatic activity and N16-VCP interactions to suppress Wallerian degeneration. J Cell Biol 2009; 184 501-513.

16. Gilley J, Coleman MP. Endogenous Nmnat2 is an essential survival factor for maintenance of healthy axons. PLOS Biol 2010; 8: e1000300.

17. Hicks AN, Lorenzetti D, Gilley J, Lu B, Andersson KE, Miligan C et al. Nicotinamide mononucleotide adenylyltransferase 2 (Nmnat2) regulates axon integrity in the mouse embryo. PLoS One 2012; 7: e47869.

18. Gilley J, Adalbert R, Yu G, Coleman MP. Rescue of peripheral and CNS axon defects in mice lacking NMNAT2. J Neurosci 2013; 33: 13410-13424.

19. Milde S, Gilley J, Coleman MP. Subcellular localization determines the stability and axon protective capacity of axon survival factor Nmnat2. PLoS Biol 2013; 11: e1001539.

20. Babetto E, Beirowski B, Russler EV, Milbrandt J, Diantonio A. The phr1 ubiquitin ligase promotes injury-induced axon self-destruction. Cell Rep 2013; 3: 1422-1429.

21. Xiong $X$, Hao $Y$, Sun $\mathrm{K}$, Li J, Li X, Mishra B et al. The highwire ubiquitin ligase promotes axonal degeneration by tuning levels of nmnat protein. PLOS Biol 2012; 10: 1001440 .

22. Yahata N, Yuasa S, Araki T. Nicotinamide mononucleotide adenylyltransferase expression in mitochondrial matrix delays Wallerian degeneration. J Neurosci 2009; 29: 6276-6284.

23. Avery MA, Rooney TM, Pandya JD, Wishart TM, Gillingwater TH, Geddes JW et al. WIdS prevents axon degeneration through increased mitochondrial flux and enhanced mitochondrial Ca2+ buffering. Curr Biol 2012; 22: 596-600.
24. Barrientos SA, Martinez NW, Yoo S, Jara JS, Zamorano S, Hetz C et al. Axonal degeneration is mediated by the mitochondrial permeability transition pore. J Neurosci 2011; 31: 966-978.

25. Araki T, Sasaki Y, Milbrandt J. Increased nuclear NAD biosynthesis and SIRT1 activation prevent axonal degeneration. Science 2004; 305: 1010-1013.

26. Wang J, Zhai $Q$, Chen $Y$, Lin E, Gu W, McBurney MW et al. A local mechanism mediates NAD-dependent protection of axon degeneration. J Cell Biol 2005; 170: 349-355.

27. Conforti L, Fang G, Beirowski B, Wang MS, Sorci L, Asress S et al. NAD(+) and axon degeneration revisited: Nmnat1 cannot substitute for WId(S) to delay Wallerian degeneration. Cell Death Differ 2007; 14: 116-127.

28. Sasaki Y, Vohra BP, Lund FE, Milbrandt J. Nicotinamide mononucleotide adenylyl transferase-mediated axonal protection requires enzymatic activity but not increased levels of neuronal nicotinamide adenine dinucleotide. J Neurosci 2009; 29: $5525-5535$.

29. Hasmann M, Schemainda I. FK866, a highly specific noncompetitive inhibitor of nicotinamide phosphoribosyltransferase, represents a novel mechanism for induction of tumor cell apoptosis. Cancer Res 2003; 63: 7436-7442.

30. Billington RA, Genazzani AA, Travelli C, Condorelli F. NAD depletion by FK866 induces autophagy. Autophagy 2008; 4: 385-387.

31. Billington RA, Travelli C, Ercolano E, Galli U, Roman CB, Grolla AA et al. Characterization of NAD uptake in mammalian cells. J Biol Chem 2008; 283: 6367-6374.

32. Watson M, Roulston A, Bélec L, Billot X, Marcellus R, Bédard D et al. The small molecule GMX1778 is a potent inhibitor of NAD+ biosynthesis: strategy for enhanced therapy in nicotinic acid phosphoribosyltransferase 1-deficient tumors. Mol Cell Biol 2009; 29: 5872-5888.

33. Nikiforov A, Dolle C, Niere M, Ziegler M. Pathways and subcellular compartmentation of NAD biosynthesis in human cells: from entry of extracellular precursors to mitochondrial NAD generation. J Biol Chem 2011; 286: 21767-21778.

34. Belenky P, Bogan KL, Brenner C. NAD+ metabolism in health and disease. Trends Biochem Sci 2007; 32: 12-19.

35. Garavaglia S, Bruzzone S, Cassani C, Canella L, Allegrone G, Sturla L et al. The high-resolution crystal structure of periplasmic Haemophilus influenzae NAD nucleotidase reveals a novel enzymatic function of human CD73 related to NAD metabolism. Biochem J 2012; 441: 131-141.

36. Belenky P, Racette FG, Bogan KL, McClure JM, Smith JS, Brenner C et al. Nicotinamide riboside promotes Sir2 silencing and extends lifespan via Nrk and Urh1/Pnp1/Meu1 pathways to NAD+. Cell 2007; 129: 473-484.

37. Coleman M. Axon degeneration mechanisms: commonality amid diversity. Nat Rev Neurosci 2005; 6: 889-898

38. Wang M, Wu Y, Culver DG, Glass JD. The gene for slow Wallerian degeneration (WId(s)) is also protective against vincristine neuropathy. Neurobiol Dis 2001; 8: 155-161.

39. Galeazzi L, Bocci P, Amici A, Brunetti L, Ruggieri S, Romine $M$ et al. Identification of nicotinamide mononucleotide deamidase of the bacterial pyridine nucleotide cycle reveals a novel broadly conserved amidohydrolase family. J Biol Chem 2011; 286: 40365-40375.

40. Beirowski B, Berek L, Adalbert R, Wagner D, Grumme DS, Addicks K et al. Quantitative and qualitative analysis of Wallerian degeneration using restricted axonal labelling in YFP. $\mathrm{H}$ mice. J Neurosci Methods 2004; 134: 23-35.

41. Formentini L, Moroni F, Chiarugi A. Detection and pharmacological modulation of nicotinamide mononucleotide (NMN) in vitro and in vivo. Biochem Pharmacol 2009; 77 : 1612-1620.

42. Vincent A, Briggs L, Chatwin GF, Emery E, Tomlins R, Oswald M et al. 2012 parkin-induced defects in neurophysiology and locomotion are generated by metabolic dysfunction and not oxidative stress. Hum Mol Genet 21: 1760-1769.

43. Natera-Naranjo O, Kar AN, Aschrafi A, Gervasi NM, Macgibeny MA, Gioio AE et al. Local translation of ATP synthase subunit 9 mRNA alters ATP levels and the production of ROS in the axon. Mol Cell Neurosci 2012; 49: 263-270.

44. Shen H, Hyrc KL, Goldberg MP. Maintaining energy homeostasis is an essential component of WId(S)-mediated axon protection. Neurobiol Dis 2013; 59: 69-79.

45. Pittelli M, Formentini L, Faraco G, Lapucci A, Rapizzi E, Cialdai F et al. Inhibition of nicotinamide phosphoribosyltransferase: cellular bioenergetics reveals a mitochondrial insensitive NAD pool. J Biol Chem 2010; 285: 34106-34114.

46. Bi J, Li H, Ye SQ, Ding S. Pre-B-cell colony-enhancing factor exerts a neuronal protection through its enzymatic activity and the reduction of mitochondrial dysfunction in in vitro ischemic models. J Neurochem 2012; 120: 334-346.

47. Wang P, Xu TY, Guan YF, Tian WW, Viollet B, Rui YC et al. Nicotinamide phosphoribosyltransferase protects against ischemic stroke through SIRT1-dependent adenosine monophosphate-activated kinase pathway. Ann Neurol 2011; 69: 360-374

48. Yoshino J, Mills KF, Yoon MJ, Imai S. Nicotinamide mononucleotide, a key $N A D(+)$ intermediate, treats the pathophysiology of diet- and age-induced diabetes in mice. Cell Metab 2011; 14: 528-536.

49. Gomes AP, Price NL, Ling AJ, Moslehi JJ, Montgomery MK, Rajman L et al. Declining NAD (+) induces a pseudohypoxic state disrupting nuclear-mitochondrial communication during aging. Cell 2013; 155: 1624-1638.

50. Osterloh JM, Yang J, Rooney TM, Fox AN, Adalbert R, Powell EH et al. dSarm/Sarm1 is required for activation of an injury-induced axon death pathway. Science 2012; 337: 481-484. 
51. Bhattacharya MR, Gerdts J, Naylor SA, Royse EX, Ebstein SY, Sasaki Y et al. A model of toxic neuropathy in Drosophila reveals a role for MORN4 in promoting axonal degeneration. J Neurosci 2012; 32: 5054-5061.

52. Coleman MP, Freeman MR. Wallerian degeneration, Wld(s), and NMNAT. Annu Rev Neurosci 2010; 33: 245-267.

53. Olesen UH, Christensen $M K$, Björkling $F$, Jäättelä $M$, Jensen $P B$, Sehested $M$ et al. Anticancer agent CHS-828 inhibits cellular synthesis of NAD. Biochem Biophys Res Commun 2008; 367: 799-804.

54. Beijers AJ, Jongen JL, Vreugdenhil G. Chemotherapy-induced neurotoxicity: the value of neuroprotective strategies. Neth J Med 2012; 70: 18-25.

55. Miledi R, Slater CR. On the degeneration of rat neuromuscular junctions after nerve section. J Physiol 1970; 207: 507-528.

56. Coleman MP, Perry VH. Axon pathology in neurological disease: a neglected therapeutic target. Trends Neurosci 2002; 25: 532-537.

57. Raff MC, Whitmore AV, Finn JT. Axonal self-destruction and neurodegeneration. Science 2002; 296: 868-871.

58. Feng G, Mellor RH, Bernstein M, Keller-Peck C, Nguyen QT, Wallace M et al. Imaging neuronal subsets in transgenic mice expressing multiple spectral variants of GFP. Neuron 2000; 28: 41-51.

59. Buckmaster EA, Perry VH, Brown MC. The rate of Wallerian degeneration in cultured neurons from wild type and C57BL/WIdS mice depends on time in culture and may be extended in the presence of elevated K+ levels. Eur J Neurosci 1995; 7: 1596-1602.

60. Balducci E, Emanuelli M, Raffaelli N, Ruggieri S, Amici A, Magni G et al. Assay methods for nicotinamide mononucleotide adenylyltransferase of wide applicability. Anal Biochem 1995; 228: $64-68$.
61. Ribchester RR, Tsao JW, Barry JA, Asgari-Jirhandeh N, Perry VH, Brown MC et al. Persistence of neuromuscular junctions after axotomy in mice with slow Wallerian degeneration (C57BL/WIdS). Eur J Neurosci 1995; 7: 1641-1650.

62. Ribchester RR, Thomson D, Wood NI, Hinks T, Gillingwater TH, Wishart TM et al. Progressive abnormalities in skeletal muscle and neuromuscular junctions of transgenic mice expressing the Huntington's disease mutation. Eur J Neurosci 2004; 20: 3092-3114.

63. O'Brien GS, Martin SM, Söllner C, Wright GJ, Becker CG, Portera-Cailliau C et al Developmentally regulated impediments to skin reinnervation by injured peripheral sensory axon terminals. Curr Biol 2009; 19: 2086-2090.

64. Gillingwater TH, Thomson D, Mack TG, Soffin EM, Mattison RJ, Coleman MP et al. Agedependent synapse withdrawal at axotomised neuromuscular junctions in Wld(s) mutant and Ube4b/Nmnat transgenic mice. J Physiol 2002; 543(Pt 3): 739-755.

(1) \&) $€$ This work is licensed under a Creative Commons Attribution-NonCommercial-NoDerivs 3.0 Unported License. The images or other third party material in this article are included in the article's Creative Commons license, unless indicated otherwise in the credit line; if the material is not included under the Creative Commons license, users will need to obtain permission from the license holder to reproduce the material. To view a copy of this license, visit http://creativecommons.org/licenses/by-nc-nd/3.0/

Supplementary Information accompanies this paper on Cell Death and Differentiation website (http://www.nature.com/cdd) 